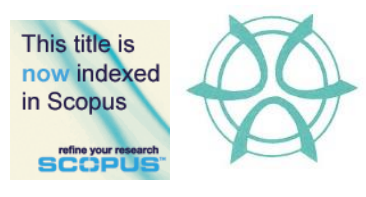

PLANNING MALAYSIA:

Journal of the Malaysian Institute of Planners

VOLUME 16 ISSUE 2 (2018), Page $63-74$

\title{
A PARAMETRIC APPROACH FOR THE STUDY OF HEAT FLOW BETWEEN STREET CANYON AND THE ATMOSPHERE
}

\author{
Muhammad Abu Eusuf ${ }^{1}$, Wira Mohd. Noor Salleh ${ }^{2}$, Abdullah Al Mamun ${ }^{3}$, \\ Adnan M. ${ }^{4}$, MSR Sabeek Eusuf ${ }^{5}$, Ataur Rahman ${ }^{6}, \&$ Mansor Ibrahim ${ }^{7}$ \\ 1,2,3,4,6 Kulliyyah of Engineering \\ INTERNATIONAL ISLAMIC UNIVERSITY MALAYSIA \\ ${ }^{5,7}$ Kulliyyah of Architecture and Environmental Design \\ INTERNATIONAL ISLAMIC UNIVERSITY MALAYSIA
}

\begin{abstract}
This paper presents the investigation results of the convective heat flow behaviour among the top of an urban street canyon and overlying atmosphere using a numerical model together with available field measurement data in variable geographical and meteorological conditions. It finds that the heat flow structure characterizes the street canyon have a strong relationship with narrowness index, outside wind velocity and latitude of the study area. The increase of the narrowness index and consequently, reduction of the sky-view factor leads to the diminution of heat flow exchange. The temperature of canyon surfaces in smaller narrowness index (n) decreases quickly to the lower degree than the temperature of the surface with larger (n) one. The increase of wind velocity outside of canyon makes this convective heat exchange flow higher, and cooler the street canyon. A parametric approach was established to evaluate this convective heat exchange flow based on the narrowness index, the latitude of the city and outside wind velocity.
\end{abstract}

Keyword: street canyon, narrowness index, convective heat flux 
PLANNING MALAYSIA

Journal of the Malaysia Institute of Planners (2018)

\section{INTRODUCTION}

Urban climate research has been carried out in two distinct scales: urban boundary layer (UBL) and urban canopy layer (UCL) (Oke, 1981). At the mesoscale, the UBL derives many of its characteristics from the interaction with the UCL beneath (Swaid, 1990), which extends vertically between the levels of zero net heat flux in the ground up to an arbitrary upper level, which is a fictitious surface, known as an urban lid and situated slightly above the roof level (Swaid $\&$ Hoffman, 2010). Within this level, all the structures at the urban surface contribute to the energy storage.

The complexity of the UCL generates an unlimited number of microclimates that prevents its study at city-scale. Thus, instead of studying the whole UCL, in the microscale the smallest division, which has common structural characteristics known as urban street canyon, is investigated. Fig. 1 shows the different geometrical aspects. Some studies have addressed the problem of heating characteristics of the canopy layer; especially the street canyon and then significant results have achieved (Yoshida, Tominga, \& Watatani, 1990; Mills, 1993; Oke, 1981; Nunez \& Oke, 1977; Sharlin \& Hoffman, 2004; Swaid \& Hoffman, 2011; Swaid \& Hoffman, 2010).

The top of UCL yields the lower boundary conditions for any model of the overlying UBL. To study the thermal characteristics at city-scale, heating characteristics of the canopy layer and heat exchange between this layer and the overlying atmosphere must be well understood. However, in a numerical model for the urban climate, to give a detail resolution in the canopy layer, the grid meshes in the horizontal direction must be much smaller than the width of the urban canyon. This usually prohibits the application of the model to a large scale due to the limitation of computational facilities. Thus, large grid meshes in the horizontal direction and enables the study of the urban thermal climate at the scale of a city. It is, therefore, evident that the quantification of the exchange processes between the top of the UCL and the overlying atmosphere at the lowest computational cost is of vital importance.

This study also attempts to provide a quantitative estimate of the convective heat exchange between the smallest division of the urban canopy layer and the overlying atmosphere through a parameterization scheme based on observed data and a numerical model. 
Muhammad Abu Eusuf, Wira M.N.S, Abdullah A.M, Adnan M., Sabeek E., Ataur R., \& Mansor I. A Parametric Approach for The Study of Heat Flow Between Street Canyon and The Atmosphere

\section{HEAT FLOW AND CHARACTERIZATION ON STREET CANYON}

Studies have revealed that the main reason for the modification of heat flow is the reduction of the fraction of the bare soil surface and the increase of paved or covered surfaces in the urban area (Yazid, Sidik, Salim, \& Saqr, 2014). Generally, for an unpaved natural ground surface, a significant portion of the net incoming radiation is converted into latent heat by evaporation \& evapotranspiration (Asaeda \& Vu, 2000) and as consequences minimal heating of the soil surface and that influence the reduction of subsurface heat storage and then convective heat exchange between the soil surface and atmosphere is small. In this case, the reheating of the atmosphere by convective heat released from the ground surface is present only during the solar hour. After sunset, surface temperature decreases quickly and soon becomes lower than that of the atmosphere. Nocturnally, the downward transfer of the convective heat from the atmosphere to the ground surface leads to the cooling of the atmosphere by the ground surface (Asaeda $\&$ $\mathrm{Vu}, 2000)$. But the situation is entirely different for a paved or covered surface. During the solar heating time, paved surface absorb a huge amount of solar insolation and since no evaporation can occur, the surface temperature becomes significantly higher than that of the overlying atmosphere. Due to higher surface temperature created more convective heat exchange between the canyon surface and the atmosphere and emitted higher net upward infrared radiation from the surface, modifying air temperature in the urban area compared with that in the rural area. Besides, the high conductivity of the pavement material helps to store a significant amount of heat flow (Asaeda \& Vu, 2000).

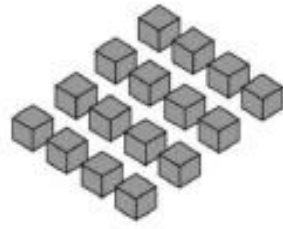

a) Building Blocks

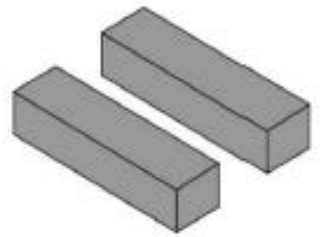

b) Urban Canyon

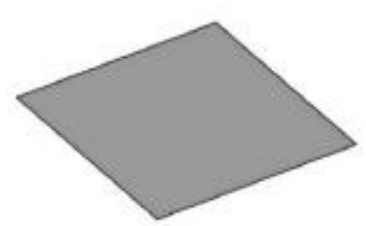

c) Urban open space

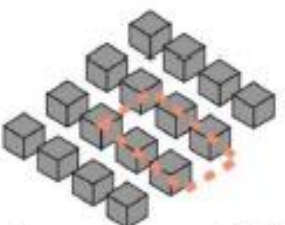

d) Urban Canyons- Group of Buildings

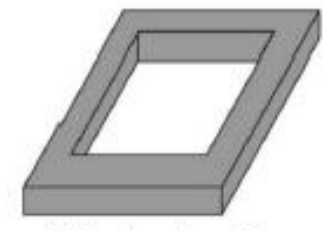

e) Courtyard or Plaza

Figure 1: Different Urban geometrical aspects in studies Source: Toparlara, Blockena, Maiheub, \& van Heijstd (2017)

The subsurface storage heat is released to the atmosphere nocturnally in the form of convective heat and upward infrared radiation. The complexity of the 
urban surface represented by urban structures can reduce the sky-view from the surface, thus trapping portion of infrared radiation emitted by the surface, and making surface temperature even higher. Hence the temperature of the atmosphere above an urban surface is higher than that above the rural surface not only during the day, but also at night.

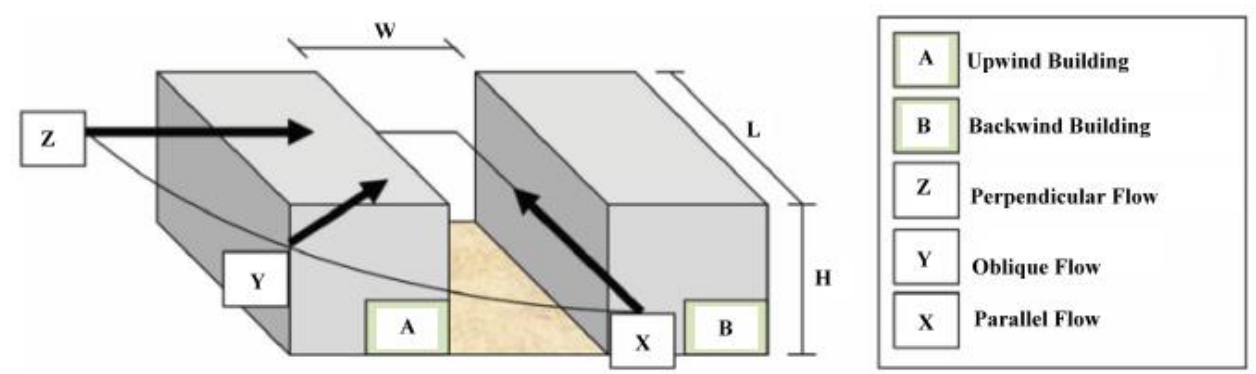

Figure 2: Geometry and flow characterization of Urban Street Canyon Source: Yazid et al. (2014)

This phenomenon is known as the urban heat island (Oke, 1981; Toparlara et al., 2017) and the difference of the air temperature with surrounding rural area is called urban heat island intensity the underground heat storage, and paved surface temperature is different for different pavement materials and canyon geometries (Vu, Asaeda, Ito, \& Armfield, 1994; Oke, 1981; Nunez \& Oke, 1977; Swaid \& Hoffman, 2011; Yazid et al., 2014) (Figure 2). Heating processes in a street canyon area very complicated due to the complexity of the wind field and the radiation condition due to the change of skyline and which affects the duration of sunshine and radiate interaction occurs between a building and front streets. Also, surfaces in a street canyon can absorb the incoming direct and diffuse solar radiation together with short-wave radiation reflected and infrared radiation emitted by the surrounding environments. This interaction is determined by narrowness index of a street canyon, which is the ratio between the average high of buildings at both sides of the street canyon and width of the street. The physical environment can change with the narrowness index, and this leads to alterations of heat energy exchange and thermal conditions. The increase of the narrowness index leads to: (i) a smaller fraction of a surface sunlit; (ii) smaller downward diffused short-wave; (iii) reduction infrared radiation to the surface in a street canyon. Consequently, the canyon surface becomes cooler during the day, which results in it smaller convective heat flow interchange among the street canyon and the overlying atmosphere. However, a street canyon with high narrowness index can trap massive portion of the infrared radiation emitted by its surfaces and slow down cooling processes after sunset. Studies have revealed that wind blowing over a street canyon creates eddies inside the street canyon whose number and intensity depends on the narrowness index $(\mathrm{Vu}$ 
Muhammad Abu Eusuf, Wira M.N.S, Abdullah A.M, Adnan M., Sabeek E., Ataur R., \& Mansor I.

A Parametric Approach for The Study of Heat Flow Between Street Canyon and The Atmosphere

et. al., 1994). It is clear that all of the factors as mentioned above must consider for the study of the canyon heating processes.

\section{FLOW OF MATERIALS}

\section{Field Observations}

Field observations were carried out at IIUM Gombak campus, Selangor, Malaysia, $3.2513^{\circ} \mathrm{N}, 101.7362^{\circ} \mathrm{E}$, to study the heating characteristic of street canyons. The observational site was near the Rectory building (known as Imam Gazzali Street - a street canyon). The narrowness index of street canyons varies between 2 to 3.0, with the North-south orientation.

During the observation, the metrological parameters were measured at $2 \mathrm{~m}$ height using hand-held KANOMAX CLIMOMASTER 6511 with the accuracy of $\pm 1 \%$. The sampling and recording rate for the sensor is 1 minute. Other parameters such as Albedo, surface temperature, etc. were also measured. Observations were carried out from January to December 2014. The weather conditions were varying from sunny, cloudy and rainy days. Since the purpose of this paper is to validate a numerical model and construct a Parametric approach between Street Canyon and the Atmosphere and the data observed from July $7^{\text {th }}$ were used to attain this validation

A sketch of the observational area and points are represented as shown in Figure 1 and Figure 2, were different geometry and flow characteristics are with various narrowness indices and orientation. Figure 2 depicts geometry and flow characteristics urban street canyon include upwind and backwind building, $\mathrm{x}-\mathrm{y}-\mathrm{z}$ flow.

As can be seen in the figure, the day was hot and sunny where air temperature and solar influx reaching more than $33^{\circ} \mathrm{C}$, close to $800 \mathrm{~W} / \mathrm{m}^{2}$ and $150 \mathrm{~W} / \mathrm{m}^{2}$ as incident and reflected radiation at noon, respectively. The meteorological conditions from 8 a.m. to 8 p.m. varies in the range from 23-33o, $85.4 \%$ to $82.8 \%$. This hot and humid weather is typical during the tropical (dry) Kuala Lumpur area. Figure 3 describes the observed diurnal solar influx: incident $(\mathrm{Si})$ and reflected radiation $(\mathrm{Sr})$.

In order to investigate the behavior of convective heat exchange between the street canyon and the boundary layer above, heating characteristics of street canyons with different narrowness indices must be investigated. However, a huge amount of observational data would be needed for this purpose. Being, a very costly and time- consuming task and basically challenging to implement in practice.

\section{Numerical Model Description}

The numerical model employed in this study is the same as that of $\mathrm{Vu}$ et al. (1994). In this model the temperature of walls and road surfaces in a long, straight street canyon is computed by solving the one-dimensional heat conduction 
equation (1) as follows:

$$
\rho c \frac{\partial T}{\partial t}=k \frac{\partial^{2} T}{\partial z^{2}}
$$

The boundary conditions at outsides surfaces of walls and road are the energy balance equation:

$$
-k \frac{\partial T}{\partial z}=S(1-\alpha)+R_{L n}-H
$$

Where, $\rho c$ is the volumetric heat capacity of the surface material; $k$ is the thermal conductivity of the surface material; $T$ is the surface temperature; $S$ is the total short-wave radiation to the surface; $\alpha$ is the canyon surface albedo; $\mathrm{R}_{\mathrm{Ln}}$ is the net infrared radiation to the surface and $\mathrm{H}$ is the convective heat flux. The temperatures inside the buildings and at depth are considered constant.

To compute the fabric (walls and road) temperature, the street canyon is divided into many horizontal and vertical elements ${ }^{4}$. Then, for each element, equation 1 is discretized in the normal direction to the element surface using a finite difference Crank-Nicholson scheme. $\mathrm{R}_{\mathrm{Ln}}$ is estimated from the following equation $(3)^{9}$.

$$
R_{L n}=\varepsilon_{i} \sigma\left[\sum_{\substack{j=1 \\ i \neq j}}^{N} \varepsilon_{j} \psi_{j i} T_{j}^{4}+\varepsilon_{a} T_{a}^{4} \psi_{S k y-i}-T_{i}^{4}\right]+\varepsilon_{i} \sigma \sum_{\substack{k=1 \\ k \neq i}}^{N} \sum_{\substack{j=1 \\ j \neq k}}^{N} \psi_{k i}\left(1-\varepsilon_{k}\right) \mu_{j k^{\varepsilon} j} T_{k}^{4}
$$

Where $i$ is the receiving surface temperature, $j$ and $k$ are the emitting surface elements to $i, T_{j}, T_{i}, T_{k}$ and $\varepsilon_{i}, \varepsilon_{j}, \varepsilon_{k}$ are the temperature and emissivity of surfaces of elements $\mathrm{i}, \mathrm{j}, \mathrm{k}$ respectively, and $\varepsilon_{a}$ is the atmospheric apparent emissivity, $T_{a}$ is the temperature outside the canyon and $\psi_{\text {sky-I }}$ is the view factor of $i$ th element for the sky and $\psi_{j i}$ is the view factor of surface element $i$ for surface element $j$. The last term of the eqn. (3) is assumed to be negligible in the 2-D canyon analysis; the first and second terms are incoming infrared radiation from the surface; and the last term is that of alternate regions. The convective heat flux $H$ from an element $i$ is estimated by the equation $4^{3}$,

$$
H=h_{c}\left(T_{a}-T_{i}\right)
$$

In equation 4 , the convective heat transfer coefficient $h_{c}$ is estimated as ${ }^{3}$ :

$$
h_{c}=0.99+0.689 u
$$

Since the purpose of this work is to establish a parameterization scheme which permits the evaluation of convective heat exchange between the street canyon and outside atmosphere, wind velocity outside the street canyon $u$ should be used in equation 5 (Nunez \& Oke, 1977).

To verify the applicability of the model for the simulation of the heating processes in a street canyon, the model was used to compute temperature at wall 
Muhammad Abu Eusuf, Wira M.N.S, Abdullah A.M, Adnan M., Sabeek E., Ataur R., \& Mansor I. A Parametric Approach for The Study of Heat Flow Between Street Canyon and The Atmosphere

and road surface at the observational site. The model has also been used to compute surface temperature in an east-west oriented street canyon for the observations reported in Yoshida et al. (1990).

\section{RESULTS AND DISCUSSION}

\section{Diurnal Variation of Heat Influx}

Figures 3 depicts the comparison between computed and observed diurnal variations of heat fluxes within the North-South oriented street canyons with the conditions reported in Yoshida et al. (1990). The convective heat flux at the top of the canyon $H_{t}$ is estimated using equation 9 in the next section; the net radiation flux $Q^{*}$ is estimated based on the computed net short-wave and infrared radiation to the street canyon; and the conductive heat flux $Q_{\mathrm{g}}$ is the difference between the net radiation (Vu et. al., 1994). Figure 5 also confirms that there is a satisfactory agreement between the computed and observed heat fluxes.

All above-mentioned facts prove that the numerical model can simulate the heating processes in a $2 \mathrm{D}$ street canyon with reasonable accuracy.

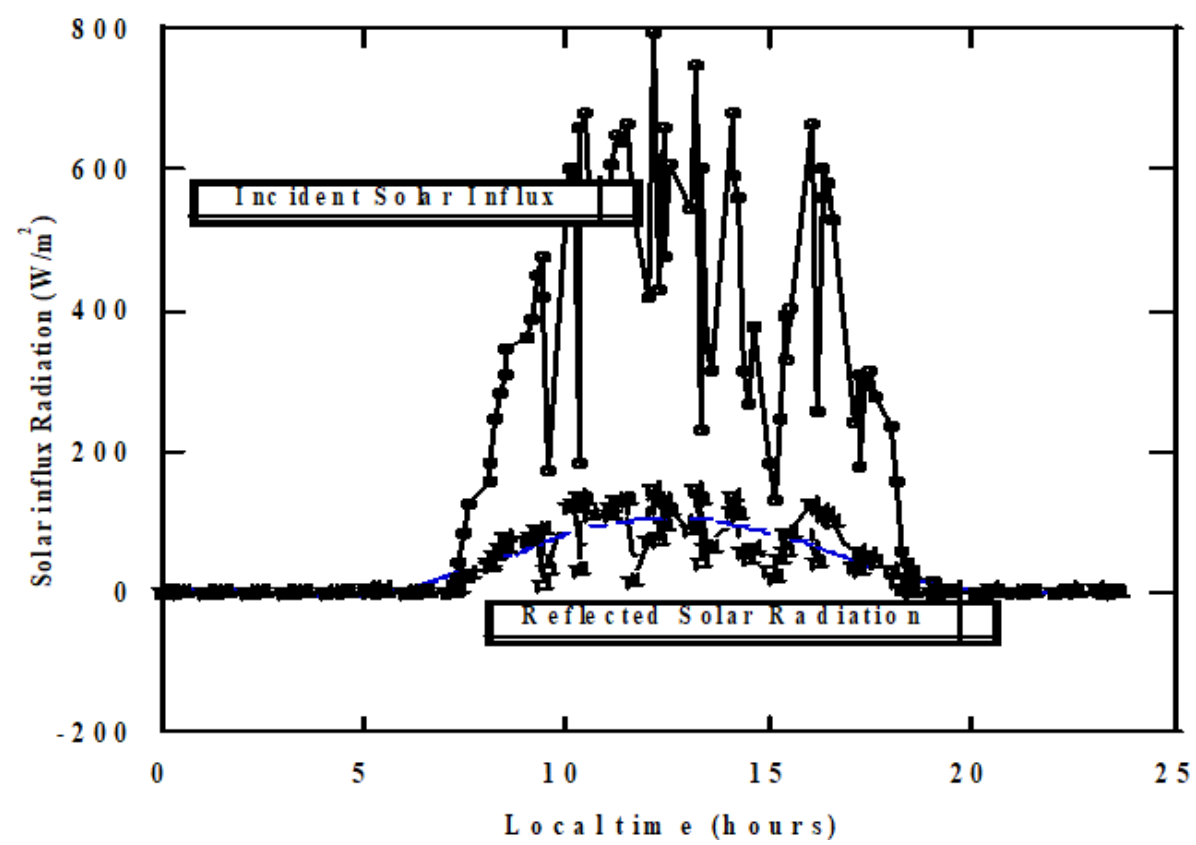

Figure 3: The observed diurnal solar influx: incident (Si-eqn 6) and reflected radiation (Sr-eqn 7) 
PLANNING MALAYSIA

Journal of the Malaysia Institute of Planners (2018)

$$
\begin{aligned}
S_{i}=0.51 \times 102 & +0.16 \times 103 t-0.945 \times 102 t 2 \\
& +0.196 \times 102 t 3-0.164 \times 10 t 4 \\
& +0.06 t 5-0.8032 \times 10-3 t 6 \\
& \text { Root mean square }(\mathrm{RMS})=90 \%(\mathrm{~A}) \\
S_{r}=0.088 \times 102 & +0.301 \times 102 t-0.182 \times 102 t 2 \\
& +0.037 \times 102 t 3-0.031 \times 10-1 t 4 \\
& +0.1136 \times 10-1 t 5-0.1522 \\
& \times 10-3 t 6
\end{aligned}
$$

$\mathrm{RMS}=91 \%(\mathrm{~B})$

$\alpha=\frac{\Sigma S r}{S i}$

Where $\alpha$ in equation 8 is the albedo or solar reflectivity coefficient for urban canyon and that $S r$ is multiple in characteristics, but for plane location $S r$ is single.

Figure 4 describes the meteorological condition of the observed area. The figure also depicts the tropical characteristics of the experimental field. In general, it is expected that air temperature at a specific point in a city influences not only by physical structures immediately surrounding but also by the heating processes at more remote locations due to heat advection by local wind. Since the wind velocity at the area mentioned above is in the range of $0.3-2 \mathrm{~m} / \mathrm{s}$, thermal advection is expected in this case.

\section{Convective Heat Flow at the Fictitious Level}

Assuming that the energy involved in advection, canyon air temperature change and radioactive flux divergence is small in comparison with the surface sources. 
Muhammad Abu Eusuf, Wira M.N.S, Abdullah A.M, Adnan M., Sabeek E., Ataur R., \& Mansor I.

A Parametric Approach for The Study of Heat Flow Between Street Canyon and The Atmosphere

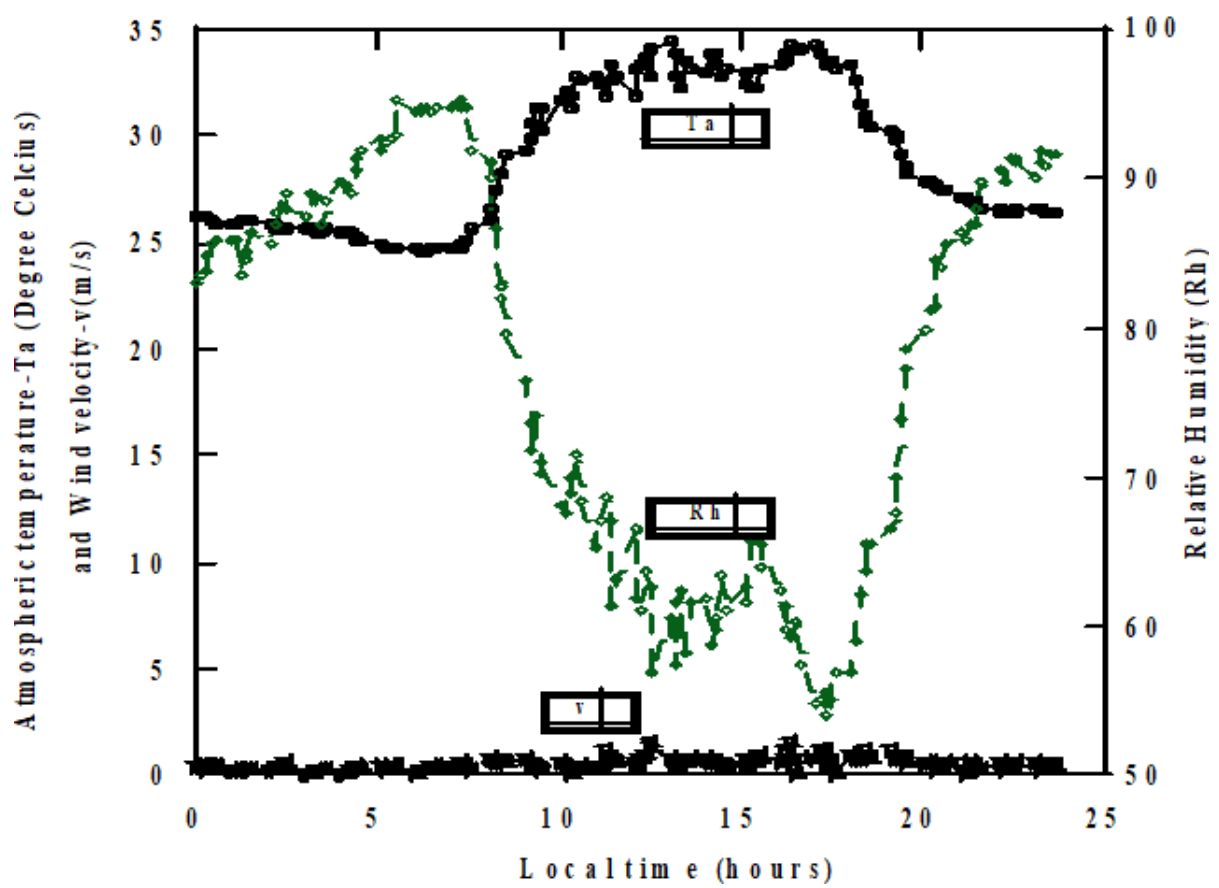

Figure 4: The meteorological conditions of the observed area

The convective heat flux through the top of the canyon can be evaluated using the convective heat fluxes at the vertical and horizontal surface as (Toparlara et al., 2017)

$H_{t}=\left\lfloor\left(H_{e}+H_{w}\right) n+H_{f}\right\rfloor /[1+2 n]$

Where $H_{e}, H_{w}$ and $H_{f}$ are the convective heat flux at the east \& west wall and the canyon, $n$ is the narrowness index of canyon which is estimated as follows (Oke, 1981; Nunez \& Oke, 1982)

$$
n=z_{b} / \omega_{s}
$$

Where, $w_{s}$ is the width of the canyon (m). $z b$ is the height of the building and it is estimated as follows (Yoshida et al., 1990)

$$
z_{b}=b x_{p}+c
$$

Where $\mathrm{b}$ is the height of the building in meters, $x_{p}$ is the number of stories and $\mathrm{c}$ is the height of basement floor (m).

\section{Parameterization of Heat Flow Structure}

As presented in previous section, for a clear summer day, the convective heat flux 
at the top of a street canyon strongly depend on the narrowness index, outside wind velocity, latitude o the place and time of the day, and the difference between air temperatures inside the street canyon and outside (Figure 5).

Parameterization For parametrization of $H_{t}$ all factors must consider. A generalized equation for the evaluation of $H_{t}$ is proposed as follows-

$$
\left.H_{t}=\mid \alpha\left(1 / n^{2}-1 / n_{o}^{2}\right) u+\beta\right\rfloor \Delta T
$$

In equation $11, \Delta \mathrm{T}$ is the air temperature difference between the imaginary surface at the top of the canyon and outside atmosphere. This temperature difference decrease to a minimum at around 06:00 and its magnitude increases rapidly during the morning hours peaking at about 13:00-14:00 near the maximum of net solar radiation.

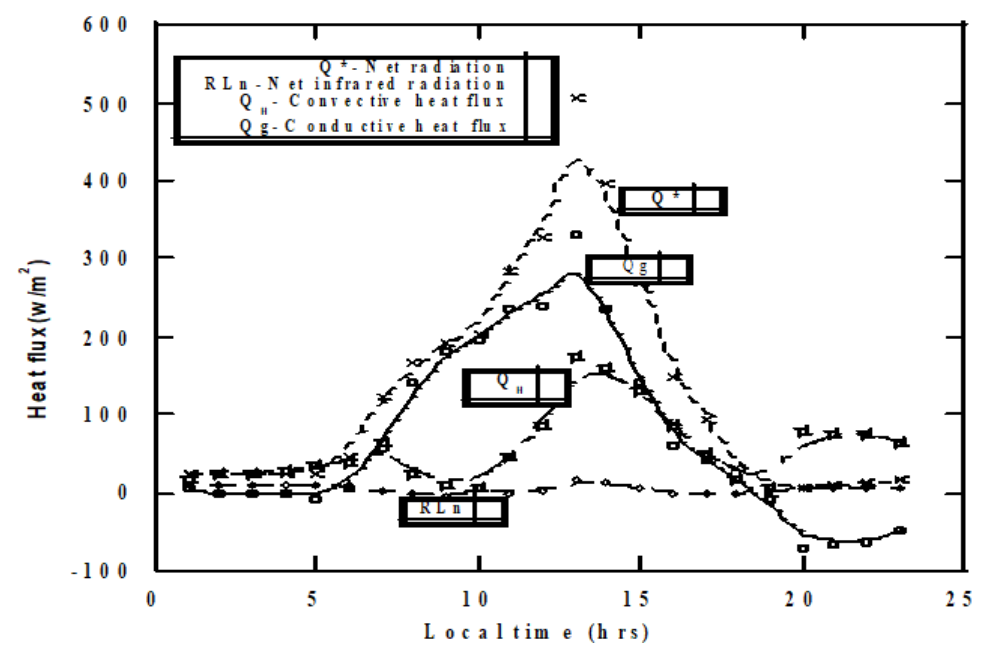

Figure 5: Parametrized the heat flow in urban canyon system

$R_{L n}$ to the surface; $\alpha$ and $\beta$ are the parametric coefficients with $\alpha=f(n, l, t, u)$ is a function of latitude, narrowness index, time and outside wind velocity, and $\beta=f(n, l)$ is a function of narrowness index and latitude; ${ }^{n_{o}}$ is the narrowness index where convective heat flux is equal to zero.

It is seen that parameterized results the best fit with the model and is closer to the field data than the results of equation 9 and Figure 5. This parameterization equation may apply to the real situation.

\section{CONCLUSION}

The formulae obtained for the convective heat exchange are ready for use in any numerical model for the urban climate. Heating processes inside a street canyon 
Muhammad Abu Eusuf, Wira M.N.S, Abdullah A.M, Adnan M., Sabeek E., Ataur R., \& Mansor I. A Parametric Approach for The Study of Heat Flow Between Street Canyon and The Atmosphere

are very complicated and a numerical model for their study must account for all factors. The heat flow among the urban canyon and overlying atmosphere strongly depends on the narrowness index, latitude, time of the day and outside mean wind velocity. Our parameterization scheme has been established to formulate the relationship between these quantities. The results of computation using this functional relationship reveal that $t$ can give a reasonable estimate of convective heat exchange between the canyon and overlying boundary layer. Since this relationship is rather simple it might be applicable for the real situation and convenient for practical use.It is expected that, in the evening, the temperature of a street canyon with small narrowness index may become lower than those in street canyon with large narrowness index. However, since no measurements were made at night, hence this assumption cannot be verified experimentally.

\section{ACKNOWLEDGEMENT}

This work was supported by Research Management Centre, International Islamic University Malaysia and Grant Nos. EDW-B14-175-1060.

\section{REFERENCES}

Asaeda, T. \& Vu, T. C. (2000). Characteristics of permeable pavement during hot summer weather and impact on the thermal environment. Building and Environment, 35(4), 363-375.

Mills, G. M. (1993). Simulating of the energy budget of an urban canyon-I. Model structure and sensitivity test. Atmospheric Environment Part B, Urban Atmosphere, 27(2), 157-170.

Nunez, M. \& Oke, T. R. (1977). The energy balance of an urban canyon. Journal of Applied Meteorology, 16(1), 11-19.

Oke, T. R. (1981). Canyon geometry and the nocturnal urban heat island: Comparison of scale model and field observations. International Journal of Climatology, 1(3), 237254.

Sharlin, N. \& Hoffman, M. E. (2004). The urban complex as a factor in the airtemperature pattern in a Mediterranean coastal region. Energy and Buildings, 149158.

Swaid, H. (1990). Thermal effects of artificial heat sources and shaded ground areas in the urban canopy layer. Energy and Buildings, 15(1-2), 253-261.

Swaid, H. \& Hoffman, M. E. (2010). Climate impacts of urban design features for high and mid-latitude cities. Energy and Buildings, 14(4), 325-336.

Swaid, H. \& Hoffman, M. E. (2011). Prediction of urban air temperature using the analytical CTTC model. Energy and Buildings, 14(4), 313-324. 
PLANNING MALAYSIA

Journal of the Malaysia Institute of Planners (2018)

Toparlara, Y., Blockena, B., Maiheub, B., \& van Heijstd, G. J. F. (2017). A review on the CFD analysis of urban microclimate. Renewable and Sustainable Energy Reviews, $80,1613-1640$

Vu, T. C., Asaeda, T., Ito, M., \& Armfield, S. (1994). Characteristics of wind field in a street canyon. Journal of Wind Engineering and Industrial Aerodynamics, 57(1), 63 80.

Yazid, A. W. M., Sidik, N. A. C., Salim, S. M., \& Saqr, K. M. (2014). A review on the flow structure and pollutant dispersion in urban street canyons for urban planning strategies. Simulation: Transactions of the Society for Modeling and Simulation International, 90(8), 892-916.

Yoshida, A., Tominga, K., \& Watatani, S. (1990). Field Measurement of energy balance of an urban canyon in the summer season. Energy and Buildings, 15(3), 417-423. 